\title{
Miastenia gravis: Un diagnóstico diferencial importante a la hora de evaluar a un paciente con sintomatología ORL
}

\author{
Myasthenia gravis: An important differential diagnosis \\ when assessing a patient with ent symptomatology
}

Diego Arancibia $\mathbf{T}^{1}$, Guillermo Til $\mathbf{P}^{1}$, Claudio Carnevale $\mathbf{S}^{1}$, Manuel Tomas $\mathbf{B}^{1}$, Sebastián Mas $\mathbf{M}^{1}$.

\begin{abstract}
RESUMEN
La miastenia gravis (MG) es una enfermedad autoinmune que afecta a la unión neuromuscular, y que se caracteriza por la presencia de autoanticuerpos dirigidos contra los receptores de membrana postsinápticos, bloqueando así la transmisión neuromuscular, y logrando de esta forma un descenso en el número de receptores en la placa neuromotora. Se presenta clínicamente como una debilidad muscular focalizada, de algunos grupos musculares, o generalizada. En el contexto ORL las presentaciones más clásicas afectan a la musculatura bulbar, presentándose como disfonía, disfagia, debilidad de la musculatura facial o la combinación de todas ellas. Presentamos 2 casos clínicos de pacientes con manifestaciones totalmente distintas de la misma enfermedad. En el primer caso se presenta a una paciente con compromiso leve de la musculatura bulbary en el segundo, un paciente con una miastenia generalizada que es internado grave en la UCI por una crisis miasténica. Realizamos una revisión bibliográfica de las últimas pruebas diagnósticas y tratamientos para la MG, y tratamos de definir los signos y síntomas que nos ayudarán como otorrinolaringólogos a un diagnóstico y tratamiento oportuno.
\end{abstract}

Palabras clave: Miastenia gravis, compromiso bulbar, disfonía, disfagia, crisis miasténica.

\begin{abstract}
Myasthenia gravis is an autoimmune disease of the neuromuscular junction, characterized by the presence of autoantibodies directed against the postsynaptic membrane receptors, blocking neuromuscular transmission in skeletal striated muscles, leading to a decrease in the number of receptors at the motor neuroplate. Clinically, myasthenia gravis presents as focalized or generalized muscle weakness. For the ENT the most frequent presentation is the bulbar involvement which presents as dysphonia, dysphagia, weakness of facial musculature or a combination of all. We report 2 cases of patients with completely different manifestations of the same disease. The first case is a patient with mild bulbar musculature compromise and the other, is a patient with severe generalized myasthenia who had to be admitted to the ICU for a myasthenic crisis.
\end{abstract}

Key words: Myasthenia gravis, bulbar involvement, dysphonia, dysphagia, myasthenic crisis.

1 Médico. Hospital Universitario Son Espases. 


\section{CASO CLÍNICO 1}

Mujer de 73 años que consulta de forma repetida a urgencias de nuestro hospital por cuadro de 1 mes y medio de evolución caracterizado por disartria (dislalia) de inicio subagudo y curso progresivo asociado a disfagia, más acentuada para sólidos con empeoramiento vespertino de los síntomas (disartria).

Valorada por especialista ORL en diferentes ocasiones se diagnostica un déficit propulsivo con posible compresión extrínseca de hipofaringe. Siendo descartado tras realización de TAC cervical.

Dada la historia y examen físico, en la cuarta visita al servicio de urgencias, el especialista ORL solicita evaluación por parte del servicio de neurología, quienes deciden su ingreso por cuadro compatible con Miastenia Gravis Bulbar. El examen neurológico de ingreso reveló leve ptosis izquierda llegando a superar el borde corneal superior tras abrir y cerrar los ojos 10 veces, y empeoramiento de la musculatura flexora cervical y de la disartria tras contar hasta 100. La analítica de urgencia y las pruebas de imagen (TAC cerebral y cervical - Rx tórax) no mostraron alteraciones de importancia.

Durante el ingreso se realizó electromiografía (EMG) que mostraba un trastorno de la transmisión neuromuscular de tipo postsináptico que apoyaba la sospecha clínica de miastenia bulbar. El estudio inmunológico reveló la presencia de anticuerpos positivos contra el receptor nicotínico de acetilcolina de músculo estriado (AChR). La tomografía axial computarizada (TAC) de tórax descartó la existencia de timoma.

Tras descartar un déficit de IgA se inició tratamiento con inmunoglobulinas (IG) ev $(0,4 \mathrm{~g} / \mathrm{kg} / \mathrm{d}$ durante 5 días), piridostigmina y corticoides.

Al alta la paciente presentaba muy discreta disartria y leve ptosis palpebral tras test de fatigabilidad, sin debilidad de la musculatura cervical.

\section{CASO CLÍNICO 2}

Varón de 70 años que ingresa en la Unidad de Cuidados Intensivos de nuestro hospital por cuadro de insuficiencia respiratoria hipercápnica asociado a fallo cardíaco que precisó reanimación cardiopulmonar (RCP) extrahospitalaria. Inicialmente se trató como un shock séptico, con necesidad de uso de drogas vasoactivas, antibioticoterapia de amplio espectro e intubación orotraqueal (IOT). Las pruebas de imagen no mostraron alteraciones (TAC cráneo-tórax, angioTAC). El estudio del líquido cefalorraquídeo tras punción lumbar fue anodino.

La evaluación neurológica mostraba un cuadro de debilidad muscular en extremidades inferiores y músculos faciales (ptosis palpebral derecha y músculos orbiculares), y disfagia. El estudio otorrinolaringológico determinó posible déficit propulsivo.

La EMG mostraba la existencia de un trastorno generalizado de la transmisión neuromuscular de probable origen postsináptico, compatible con miastenia gravis. Se inició plasmaféresis asociada a prednisona $1 \mathrm{mg} / \mathrm{kg}$. El estudio de anticuerpos mostró AChR + y anti-MUSK negativos.

Tras el inicio del tratamiento el paciente evolucionó favorablemente con remisión de la debilidad muscular generalizada y el compromiso ventilatorio. El interrogatorio dirigido reveló una historia de 6 meses de evolución caracterizada por pérdida de peso $(40 \mathrm{~kg})$, disfagia progresiva, alteración del tono de voz y debilidad de extremidades.

A lo largo de los días el paciente presentó una mejoría clínica sustancial, mostrándose orientado y colaborador, sin alteración del lenguaje. No presentaba ptosis palpebral ni asimetría facial, solo un ligero exoftalmos.

\section{MIASTENIA GRAVIS}

La miastenia gravis (MG) es una enfermedad autoinmune que afecta a la unión neuromuscular, y que se caracteriza por la presencia de autoanticuerpos dirigidos contra los receptores de membrana postsinápticos, bloqueando así la transmisión neuromuscular, y logrando de esta forma un descenso en el número de receptores en la placa neuromotora ${ }^{1}$. Esta disminución de los receptores postsinápticos se manifiesta como debilidad y fatiga de la musculatura voluntaria, que empeora con la actividad y mejora con el reposo. La miastenia gravis tiene una prevalencia estimada a nivel mundial entre 15 a 179 por cada millón de habitantes².

Clínicamente, la MG se presenta como una debilidad muscular focalizada, con alteraciones 
oculares motoras (ptosis y diplopia) en aproximadamente $50 \%-60 \%$ de los pacientes al momento del diagnóstico ${ }^{2}$. El compromiso bulbar se presenta como disfonía, rinolalia, dificultad para mantener el tono de la voz, fatiga vocal, afonía intermitente, estridor, disfagia (dificultad para tragar), debilidad de la masticación, y debilidad de la musculatura facial, hasta en $27 \%$ de los casos en el diagnóstico inicial ${ }^{3-5}$.

La debilidad de la musculatura de los miembros, sobre todo musculatura proximal y cervical, se presenta de forma inicial hasta en $10 \%$ de los casos.

Esta enfermedad tiene un carácter progresivo y puede llegar a transformarse en una afectación generalizada con el paso del tiempo. En $15 \%$ de los pacientes puede ocurrir una debilidad respiratoria aguda que puede llevarlos hasta la muerte, llamada crisis miasténica².

El diagnóstico se basa en la historia clínica y el examen neurológico, y se confirma mediante la electromiografía de estimulación repetida y la presencia de autoanticuerpos dirigidos contra proteínas en la membrana postsináptica de la unión neuromuscular ${ }^{3}$.

Actualmente el diagnóstico de MG no recae en la respuesta positiva a la inyección de acetilcolinesterasa de acción rápida (test de Edrofonio). Los pacientes con anticuerpos positivos contra el receptor nicotínico de acetilcolina de músculo estriado (AChR) tienen una respuesta mayor al $90 \%$, en cambio los MuSK+ responden en menos de $50 \%$ de los casos.

La mayoría de los pacientes con MG generalizada $(85 \%)$ y $M G$ ocular pura $(50 \%)$ tendrá anticuerpos positivos contra el receptor nicotínico de acetilcolina de músculo estriado (AChR).

El $8 \%-10 \%$ adicional de los pacientes con enfermedad generalizada tienen anticuerpos positivos contra el receptor de tirosina quinasa músculo específico (MuSK).

Los MuSK+ constituyen alrededor del $40 \%$ de los pacientes AChR-negativas con MG en todas sus formas². A pesar de que la positividad de los anticuerpos AChR y MuSK+ son confirmatorios en el diagnóstico de la MG, alrededor del $10 \%$ de los pacientes permanecerán con los anticuerpos negativos. Una lipoproteína de baja densidad relacionada con el receptor de proteína 4 (Lrp4) ha sido descubierta recientemente, y se cree que podría encontrarse en los pacientes con MG doblemente seronegativos (anticuerpos AChR y MuSK+)2.

El tratamiento de la miastenia gravis se basa en un tratamiento médico, y como primera línea se utilizan fármacos inhibidores de la acetilcolinesterasa como la piridostigmina o la neostigmina, los cuales proveen alivio sintomático pero no alteran el curso de la enfermedad ${ }^{2}$. Muchos pacientes tienen buena respuesta a terapias inmunosupresoras como la prednisona e inmunomoduladores como la azatioprina, ciclosporina y micofenolato². Tratamientos biológicos como el rituximab, usados en otros desórdenes autoinmunes mediados por anticuerpos, han demostrado ser efectivos y han permitido disminuir las dosis de corticoides 0 inmunosupresores usados para el tratamiento².

Las crisis miasténicas precisarán el uso de terapias con inmunoglobulinas o plasmaféresis.

A pesar de que la timectomía es considerada el tratamiento estándar en el 10\%-20\% de los casos de MG con timoma, el rol de la timectomía no está totalmente aclarado, y generalmente no se considera apropiado para las formas oculares puras de MG.

\section{DISCUSIÓN}

La miastenia gravis es una patología de escaso diagnóstico por parte de los otorrinolaringólogos, ya que su forma de presentación, que puede ser muy variada, sumado a un escaso conocimiento por parte de nuestra especialidad, hacen muy factible que la mayoría de casos pasen desapercibidos, y solo se diagnostiquen y traten signos, más que a la enfermedad como tal.

En este artículo presentamos 2 casos que fueron valorados en varias ocasiones por diferentes especialistas en $\mathrm{ORL}$, no logrando en ningún caso sospechar el diagnóstico de MG.

La MG bulbar presenta una sintomatología "típica" de la esfera ORL. Siendo la disartria, disfagia, rinolalia o debilidad de la musculatura facial signos característicos de estos pacientes, que sumados a una historia clínica corcondante y detallada, nos ayudará a ser más precisos en el diagnóstico, cuando tenemos en mente esta enfermedad como diagnóstico diferencial. 
A pesar de ser una patología que normalmente diagnostica y trata neurología, creemos que es de vital importancia manejar las formas de presentación, la probable evolución, pruebas diagnósticas y los probables tratamientos actuales que se le pueden ofrecer al paciente con MG, no solo para un diagnóstico oportuno sino también para guiar al paciente durante las distintas etapas de su enfermedad.

\section{REFERENCIAS}

1. Mao Vh, Abaza M, R. Spiegel J, Mandel S Hawkshaw M, J. Heuer R, and T. Sataloff R. Laryngeal Myasthenia Gravis: Report of 40 Cases. Department of Otolaryngology-Head and Neck Surgery, and Department of Neurology, Thomas Jefferson University, Philadelphia, Pennsylvania. Journal of Voice 2001; 15(1): 122-30.

2. M Statland J, Ciafaloni E. Myasthenia gravis, Five new things. Neurology Clinical Practice. April 2013.

3. Hartl D, Leboulleux S, Klap P, Schlumberger M. Myasthenia gravis mimicking unilateral vocal fold paralysis at presentation. The Journal of Laryngology \& Otology 2007; 121, 174-8.

4. Carpenter RJ, McDonald T, Howard FM. The Otolaryngologic presentation of Myasthenia Gravis. The Laryngoscope 1979; 89: 922-8.

5. Bravo-Domínguez 0 , Foglia-Fernández M, GonzálezCompte X, Jimenez-Montoya R, Girons Bonells J, DicENTA-SOUSA M. Otolaryngological presentation of Myasthenia Gravis. Acta Otorrinolaring Esp 2000; 51(6): 549-51.

6. Sharp HR, Degrip A, Mitchell DB, Heller A. Bulbar presentations of myasthenia gravis in the ederly patient. The Journal of Laryngology \& Otology 2001; 115: 1-3.

7. Salazar-Cabrera C, De Saa-Alvarez M, AparicioPérez M, Marcos-Calle J, García B. Myasthenia Gravis: The Otolaryngologist's Perspective. Otolaryngology 2002; 23: 169-72. 